\title{
Oncolytic Poliovirus Therapy in a Mouse Model of Neuroblastoma: Preclinical Data Analysis and Future Studies
}

\author{
Hidemi Toyoda, Eckard Wimmer and Jeronimo Cello \\ Department of Molecular Genetics and Microbiology, Stony Brook University \\ Stony Brook, NewYork \\ USA
}

\section{Introduction}

Neuroblastoma, a malignant embryonal tumor of the neural crest cells, is one of the most common solid extracranial tumors of early childhood (Brodeur et al., 2006). The prevalence of neuroblastoma in children is 7.5 cases /100, 000 infants (Brodeur et al., 2006; Gao et al, 1997; Gurney et al., 1997; Spix et al., 2006). Furthermore, the annual incidence of this tumor is nearly 1.0/100,000 children under the age of 15 years (Ries et al., 2005). Neuroblastoma comprises about $8-10 \%$ of all childhood cancers and for approximately $15 \%$ of cancer deaths in children (Gao et al., 1997; Ries et al., 2005). Neuroblastoma can arise anywhere along the sympathetic nervous system. Fifty percent of the tumors originate in the adrenal medulla. Additional sites of origin include the nerve tissue in the chest, neck, pelvis or abdomen (Ries et al., 2005). Clinical presentation of neuroblastoma is highly variable and is dependent on the site of the primary tumor, as well as on the disease extent and on the absence or presence of paraneoplastic syndromes (Maris \& Matthay, 1999; Park et al., 2008). The three main clinical scenarios are: localized, metastatic and $4 S$ ( $\mathrm{S}$ for special).

In contrast to many other pediatric malignancies, progress in treatment of neuroblastoma (especially for advanced-stage tumors) has been relatively modest. Hence, at present, this tumor still poses a major challenge to the pediatric oncologist. Current treatment strategies include any or all of the following; watchfulwaiting, surgery, mild to aggressive chemotherapy, radiotherapy, and bone marrow transplants. Several new agents and combinations are in ongoing trials for relapsed neuroblastoma, including topoisomerase 1 inhibitors, radionuclides, histone deacetylase and tyrosine kinase inhibitors, monoclonal antibodies directed to disialoganglioside, and angiogenesis inhibitors (Maris \& Matthay, 1999). As neuroblastoma is a disease that most often strikes young children, treating patients with aggressive therapy is a concern because of the potential for long-term health implications (from heart disease to second malignancies). Some children with neuroblastoma can be cured, and for these children, oncologists must try to give the minimum treatment possible while achieving cure. Although a fraction of the patients are cured with current treatments, approximately 40 per cent will die of this disease; for these patients improved treatment options are imperative (Matthay et al., 1999, 2009). 


\section{Virotherapy for cancer}

Poor response to conventional treatment is not only observed in neuroblastoma but also in many prevalent tumors. In fact, despite aggressive radio-and chemotherapy, the long-term survival from common cancers such as prostate, breast, colorectal and lung has barely budged since the 1970s (Leaf, 2004). Therefore new cancer treatments with novel mechanisms of action are needed.

Such new treatments may be based on human non-pathogenic and pathogenic viruses (for review see Kirn et al., 2001; Parato et al., 2005; Vähä-Koskela et al., 2007). An oncolytic virus is a replicating agent that has either been naturally selected or engineered to single out and destroy tumor cells. For a long time, viruses have been under scrutiny for their potential antineoplastic effects (Sinkovics and Horvath, 1993). Historically, human trials were initiated with several potential oncolytic viruses during the 1950' and 1960's. Among the first viruses to be tested as oncolytic agents were rabies virus (DePace, 1912; Pack, 1950), several adenovirus serotypes (Huebner et al., 1956; Southam et al., 1952), mumps virus (Asada, 1974; Okuno et al., 1978), and West Nile virus (Southam \& Moore, 1952). Moreover, 19 different viruses were evaluated in patients suffering from various types of cancer (Newman \& Southam, 1954; Wheelock \& Dingle, 1964). In general, the outcome of these treatments were tantalizing, but ultimately disappointing and the approach was temporarily abandoned. The onset of the gene therapy era in 1990s reinvigorated the field of viral therapy for cancer (virotherapy). Many of the basic principles of virus-mediated oncolysis apply equally to gene therapy vectors and oncolytic viruses. The main advantage of replication-competent oncolytic viruses over non-replicanting viral gene therapy is the ability to propagate and spread from the site of inoculation throughout tumor mass and beyond. Following the successful attempt to engineer a Herpes virus simplex-1 (HSV-1) mutant that selectively destroyed brain tumor cells (Martuza et al., 1991), the field of virotherapy has expanded considerably. There are now more 90 different DNA and RNA virus variants that have been tested for anti-tumor efficacy in animals and humans (for comprehensive list of oncolytic viruses see Kirn et al., 2001; Parato et al., 2005; Vähä-Koskela et al., 2007). Furthermore, more than 20 different oncolytic viruses have entered clinical trials (for review see Kirn et al., 2001; Parato et al., 2005; Vähä-Koskela et al., 2007).

Oncolytic viruses replicate preferentially in cancer cells because they are taking advantage of the same cellular defects that lead to tumor growth. Viruses that are not inherently selective for cancer cells can often be modified and engineered for tumor-selectivity. Generally, four main approaches have been described in the control of tumor progression through virotherapy: 1) the use of naturally occurring oncolytic viruses; e.g., Newcastle diseases virus (NDV) (Lorence et al., 1988); reovirus (Coffey et al., 1998), and vesicular stomatitis virus (VSV) (Stojdl et al., 2000); 2) engineered viruses with incorporate tissuespecific promoters that limit to tumor cells the expression of genes necessary for replication, e.g., HSV (Miyatake et al., 1997) and adenovirus (Hallenbeck et al., 1999); 3) modification of the viral coat to target uptake specifically to tumor cells, e.g., measles (Hammond et al, 2001); and 4) deletion of entire genes or functional gene regions that are necessary for efficient replication and/or toxicity but are nonessential in cancer cells, e.g., vaccinia virus (Mastrangelo et al., ) and adenovirus (Bischoff et al., 1996).

Oncolytic viruses are multimodality therapeutics that can be exploited as a treatment platform for cancer. One advantage of virotherapy is its use in combination with conventional chemo-, radio-or immunotherapy (Aghi \& Martuzza, 2005; Kottke et al., 2008; Kumar et al., 2008; 
Nandi et al., 2008). Another advantage of oncolytic viruses is the capacity to trigger tumor destruction by different mechanisms including stimulation of innate and adaptive immunity that have the potential anticancer activity (Bell et al., 2003). Despite the impressive improvements made in the field of virotherapy, the use of oncolytic viruses still face important hurdles in cancer therapy. Some of these problems are incomplete transduction, poor systemic distribution, immune response, intratumoral spread, and safety. These issues have to be resolved before oncolytic viral products became approved therapeutics.

\section{Oncolytic poliovirus for treatment of neuroblastoma: Preclinical studies}

Poliovirus (PV) has recently been added to the list of viruses that hold promise as possible agents in tumor therapy (Gromeier et al., 2000; Ochiai et al., 2004). A nonenveloped, plusstranded enterovirus of the Picornaviridae family, poliovirus replicates in the gastrointestinal tract causing little, if any, clinical symptoms. Rarely (at a rate of $10^{-2}$ to $10^{-3}$ ), the virus invades the central nervous system (CNS) where it targets predominantly motor neurons, thereby causing paralysis and even death (Mueller et al., 2005). Generally, poliovirus replicates efficiently in nearly all tumor cell lines tested, which has led to the suggestion that it may be suitable for the treatment of different cancers. However, the possibility that poliovirus can cause poliomyelitis calls for significant neuroattenuation to avoid collateral neurologic complications in cancer treatment. Therefore, the aim of our previous study was to develop highly attenuated polioviruses that may be suitable for the treatment of neuroblastoma in children (Toyoda et al., 2007). It was of concern, however, that the high coverage of antipolio vaccination in early childhood may interfere with the application of poliovirus in tumor therapy. Therefore, we also aimed to develop an immunocompetent animal model that would allow us to investigate the oncolytic capacity of neuroattenuated polioviruses for the treatment of neuroblastoma in the presence of high titers of poliovirus neutralizing antibodies (Toyoda et al., 2007). As shown by us and other investigators, pathogenesis of neurotropic viruses including poliovirus can be controlled by translation (Gromeier et al., 1996, 2000; Mohr, 2005). In poliovirus, an exchange of the internal ribosomal entry site (IRES) within the 5'-nontranslated region (NTR) with its counterpart from human rhinovirus type 2 (HRV2), another picornavirus, yielded viruses [called PV1(RIPO)] that are highly attenuated in mice transgenic for the human poliovirus receptor (PVR) CD155 (CD155 tg mice; Gromeier et al., 1996, 1999) yet replicate efficiently and lytically in cell lines derived from malignant glioma and breast cancer (Cello et al., 2008; Gromeier et al., 1996, 2000; Ochiai et al., 2004, 2006). However, PV1(RIPO) and PVS(RIPO), a derivative of PV1(RIPO) that is currently under investigation for the treatment of glioma, grow poorly in neuroblastoma cells (Cello et al., 2008; Gromeier et al., 1996, 2000;). This observation prompted us to search for other poliovirus derivatives with oncolytic properties against neuroblastoma. The whole genome synthesis of poliovirus (Cello et al., 2002) produced the surprising observation that a point mutation (A103G) in a "spacer region" between the cloverleaf and IRES in the 5'-NTR that was introduced as genetic marker attenuated poliovirus 10,000-fold (De Jesus et al., 2005). We found that the A103G variant of poliovirus replicates well in human neuroblastoma cell lines at $37^{\circ} \mathrm{C}$ (De Jesus et al., 2005). However, the attenuating mutation A103G in the spacer region was unstable on replication and direct revertant variants that had acquired the neurovirulent phenotype of wild-type (wt) poliovirus type 1 (Mahoney) [PV1(M)] (Fig. 1A ) were readily scored (De Jesus et al., 2005). We reasoned that a stable attenuation phenotype could be generated if the spacer 
region would be interrupted by an essential RNA replication element that the virus cannot afford to delete. Such an element is the cre, a stem-loop structure mapping to the coding region of viral protein 2CATPase (Fig. 1B; Paul, 2002). Cre is absolutely required for poliovirus genome synthesis (Paul, 2002). Based on this concept, we have developed a stable attenuated poliovirus, replicating in neuroblastoma cells, by introducing the cre element into the spacer region between the cloverleaf and IRES in the 5'-NTR (mono-crePV) at the 104-nucleotide locus (Fig 1B) (Toyoda et al., 2007).

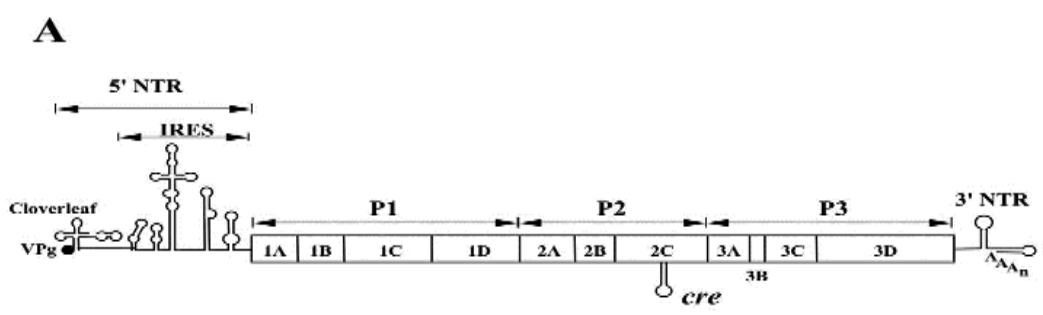

\section{B}

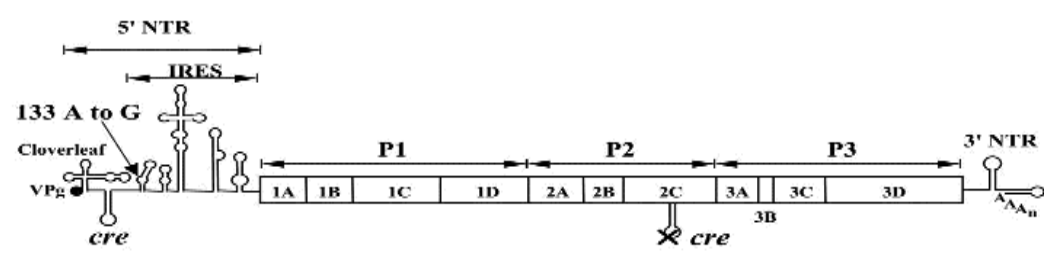

Fig. 1. Schematic diagram of full-length poliovirus genomes. (A) Genomic structure of PV1(M). The 5' end is terminated with the genome-linked protein VPg and the $3^{\prime}$ end with polyadenylic acid. The $5^{\prime}$ NTR, harboring the cloverleaf and the IRES, is followed by the single open reading frame (open box) encoding the viral polyprotein, and the $3^{\prime}$ NTR. The cis replication element ( $\mathrm{cre}$ ) is indicated as an open stem-loop in the poliovirus polyprotein below polypeptide 2C. The polyprotein contains (Nterminus to C-terminus) structural (P1) and non-structural (P2 and $\mathrm{P} 3$ ) proteins that are released from the polypeptide chain by proteolytic processing. (B) Structure of A133G mono cre PV genomic RNA. The naïve cre in $2 \mathrm{C}$ was inactivated through three mutations G4462A C4465U A4472C of the poliovirus-cre loop. The cis replication element (cre) was inserted between cloverleaf and IRES. A point mutation was engineered at nt133 (A to G) of mono-cre PV.

To induce neuroblastoma in our animal model we used a mouse neuroblastoma cell line stably expressing CD155 $\propto$ (Neuro-2aCD155). Neuro2aCD155 cell line was developed in our laboratory and is susceptible to poliovirus infection (Mueller \& Wimmer, 2003). Using the nude mice model, we and others have shown previously that tumors of human origin can be successfully treated with neuroattenuated poliovirus strains, that is with PV(RIPO) derivatives (Groemeier et al., 2000), or with the Sabin vaccine strains (Toyoda et al., 2004). However, in the nude mice the lack of a possible immune response to the oncolytic agents mitigates the importance of the results. Therefore, we constructed fully immunocompetent mice (CD155 tg A/J mice) that express CD155 and accept Neuro-2aCD155 cells for the 
formation of lethal neuroblastoma (Toyoda et al., 2007). Using this animal model, we demonstrated that Neuro-2aCD155 subcutaneous tumors of Neuro-2aCD155 cells were eliminated by intratumoral administrations of a variant of mono-crePV ( $\left.\mathrm{A}_{133} \mathrm{Gmono}-\mathrm{crePV}\right)$ (Toyoda et al., 2007). Interestingly, we observed the complete regression of the established lethal subcutaneous Neuro-2aCD155 tumors without neurologic side effects despite the presence of high titers of anti-poliovirus antibodies (Toyoda et al., 2007). This result indicates that anti-polio response induced by immunization can exert protection against poliomyelitis without compromising the oncolytic capacity of poliovirus. Remarkably, the tumor-bearing mice, which were cured through treatment with $\mathrm{A}_{133} \mathrm{Gmono}-\mathrm{crePV}$, resisted attempts to reestablish neuroblastoma with Neuro-2aCD155 cells. We hypothesized that destruction of tumor cells by $\mathrm{A}_{133} \mathrm{Gmono}-\mathrm{crePV}$ can increment the release of tumor antigens which may induce a more efficient antigen presentation and the development of a robust antitumor immunity (Toyoda et al., 2007).

Based on these results, we proposed to characterize the antitumor immune response evoked by the treatment of subcutaneous neuroblastoma by $\mathrm{A}_{133} \mathrm{Gmono}-\mathrm{crePV}$. To evaluate the cellular anti-tumor immunity induced by oncolytic therapy with live attenuated poliovirus, we quantified the cytolytic anti-tumor activity of splenocytes collected from the neuroblastoma-implanted CD155 tg A/J mice cured by four intratumoral inoculations of $\mathrm{A}_{133} \mathrm{Gmono}-\mathrm{crePV}$. Mock-treated mice received equivalent intratumoral injections of PBS. These animals were killed after the tumor had reached a volume of $\sim 500 \mathrm{~mm}^{3}$ and their splenocytes were used as a control in cytotoxic assays. The development of tumor specific cytotoxicity was assessed by standard lactate dehydrogenase-release assays (Decker \& Lohmann-Matthes, 1988). Splenocytes isolated from mice cured from neuroblastoma exhibited significantly higher lytic activity against both target cells tested (Neuro-2aCD155 and Neuro-2a) than did those from splenocytes derived from control mice $(16.0 \%$ vs $1.5 \%$, $\mathrm{P}<0.001)$. Thus, this result confirmed that treatment with a neuroattenuated oncolytic PV strain induces antitumor immunity against neuroblastoma (Toyoda et al., 2011).

To determine which cell subpopulations are responsible for the cell-mediated antitumor immune responses, splenocytes from the cured mice were depleted in vitro of NK, CD4+ or CD8+ cells respectively, prior to cytotoxic assay. As shown in Fig. 2, incubation of splenocytes with neutralizing antibody NK1.1 or anti-CD4 had little or no effect on their ability to kill Neuro-2aCD155 cells. In contrast, depletion of CD8+ cells abrogated the cytolytic activity of splenocytes from cured mice by about $70 \%$ compared to non-depleted splenocytes (Fig. 2). These data indicate that cytotoxic CD8+ $\mathrm{T}$ cells are the principal mediators of antineuroblastoma immunity elicited by $\mathrm{A}_{133} \mathrm{Gmono}-\mathrm{crePV}$ virotherapy (Toyoda et al., 2011)

Any firm conclusion about the capacity of $\mathrm{A}_{133} \mathrm{Gmono}$-crePV induced antitumor immunity requires direct demonstration of that ability. We thus adoptively transferred the splenocytes harvested from mice cured of neuroblastoma by four $\mathrm{A}_{133} \mathrm{Gmono}-\mathrm{crePV}$ inoculations into mice that had developed subcutaneous Neuro-2aCD155 tumor. Splenocytes from naïve mice served as a negative control. Splenocytes from cured or naïve mice were adoptively transferred by tail vein injection ( $2 \times 10^{7}$ splenocytes in $100 \mu \mathrm{l}$ of PBS) to neuroblastoma implanted mice when their subcutaneous tumor volumes were $\sim 170 \mathrm{~mm}^{3}$. After the splenocyte transfer, tumor sizes were measured and tumor volumes calculated every day. Our results showed that adoptive transfer of splenocytes from $\mathrm{A}_{133}$ GmonocrePV-treated mice produced a significant inhibition of tumor growth by comparison with the negative 
control (average tumor volume: $583 \mathrm{~mm}^{3}$ vs. $2183 \mathrm{~mm}^{3}, \mathrm{p}<0.01$ at day 10 post splenocytes transfer) (Toyoda et al., 2011). This result confirms that oncolytic therapy for neuroblastoma with attenuated poliovirus induces tumor-specific immune response.

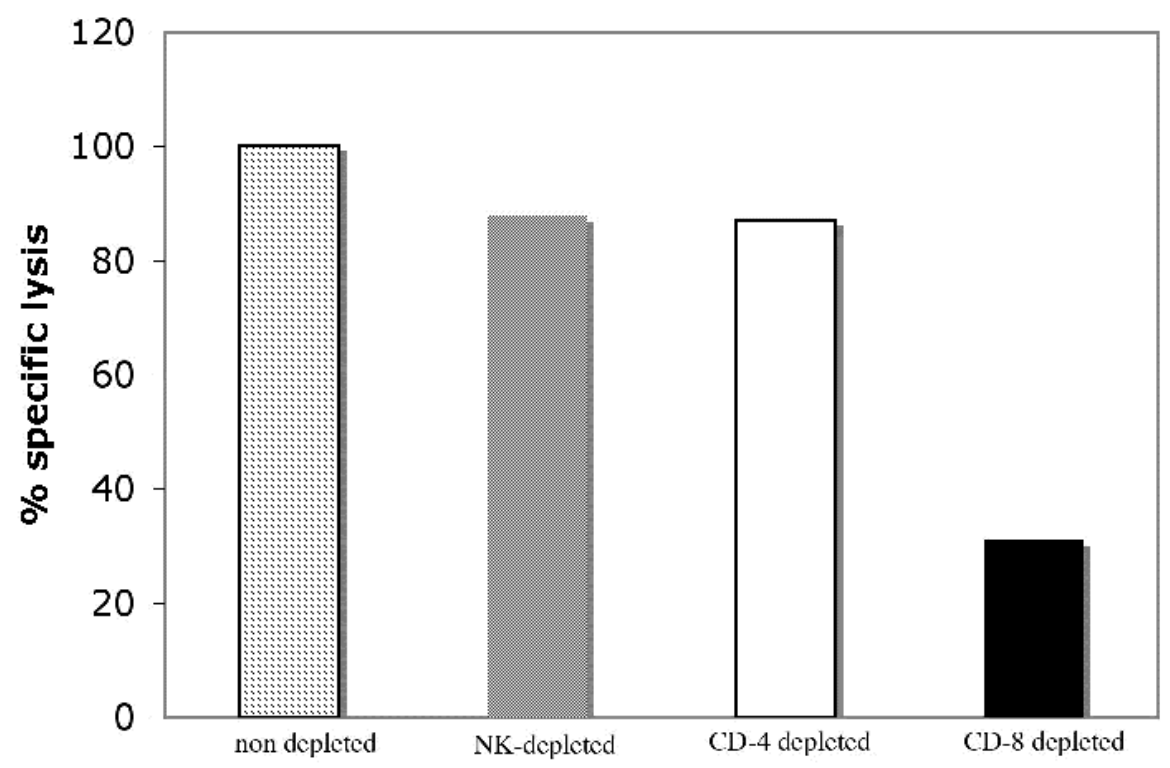

Fig. 2. Characterization of effector cytotoxic cells. Mice were sacrificed 2 months after tumor rechallenge. Splenocytes purified from the mice were incubated with neutralizing antibody against CD4, CD8, NK or PBS (as control) and then tested for cytotoxicity against Neuro2aCD155 cells.

In line with our findings, previous investigations in mice and humans have also shown that treatment with oncolytic viruses can result in the enhancement of antitumor immune response (Diaz et al., 2007; Greiner et al., 2006; Moehler et al., 2005; Liu et al., 2007a, 2007b; Qiao et al., 2008; Toda et al., 1999).

Tumor destruction by an oncolytic virus can release a wide range of tumor specific antigens that will be taken up by infiltrating antigen-presenting cells for cross-presentation to $\mathrm{T}$ cells for priming of antigen-specific immune response ( $\mathrm{O}^{\prime}$ Shea, 2005). Moreover, different stimuli can promote an immunogenic cell death of tumor cells. Immunogenic cell death implies that dying tumor cells release several cellular signals that will facilitate immune recognition and elimination of tumor cells (Obeid et al., 2007a, 2007b). Noteworthy, it has been speculated that virus infection of tumor cells may induce an immunogenic cell death (Blachere et al., 2005). Based on these premises, we reasoned that immunization with in vitro PV-infected neuroblastoma cells should be able to prime an effective immune response against tumor cells and subsequently hinder neuroblastoma growth. To this end, 3 freeze-thaw cycles followed by 10 strokes of dounce homogenizer were performed for preparation of noninfected and PV-infected Neuro-2aCD155 lysates. The poliovirus titer in the PV-infected Neuro-2aCD155 lysate was $5 \times 10^{8} \mathrm{pfu} / \mathrm{ml}$. For the tumor rejection assays, polio Neuro-2aCD155 immunized CD155 tgA/J mice were injected intraperitoneally with PV-infected lysate, or 
noninfected Neuro-2aCD155 lysate, or a mixture of noninfected Neuro-2aCD155 lysate plus poliovirus (poliovirus titer in the mixture was $5 \times 108 \mathrm{pfu} / \mathrm{ml}$ ) or PBS thrice at 1-week interval. All mice were injected intravenously with $2 \times 10^{6}$ Neuro-2aCD155 cells 21 days after last vaccination. Survival of the mice was monitored.

Examination of dead mice showed multiple liver and perirenal tumors. Analysis of KaplanMeier curves using the log-rank test showed no difference in the survival kinetics among mice immunized with PBS, noninfected Neuro2aCD155 lysate and the mixture of noninfected Neuro-2aCD155 lysate and poliovirus ( $p>0.05$, Fig 3). All mice from these groups died before 90 days of tumor challenge. In contrast, $70 \%$ of mice immunized with PV-infected Neuro-2aCD155 lysate, survived beyond 100 days after tumor challenge. Furthermore, statistical analyses showed that immunization with PV-infected Neuro$2 \mathrm{aCD} 155$ lysate was superior to each immunization with other lysate or PBS ( $<<0.01$, Fig 3).

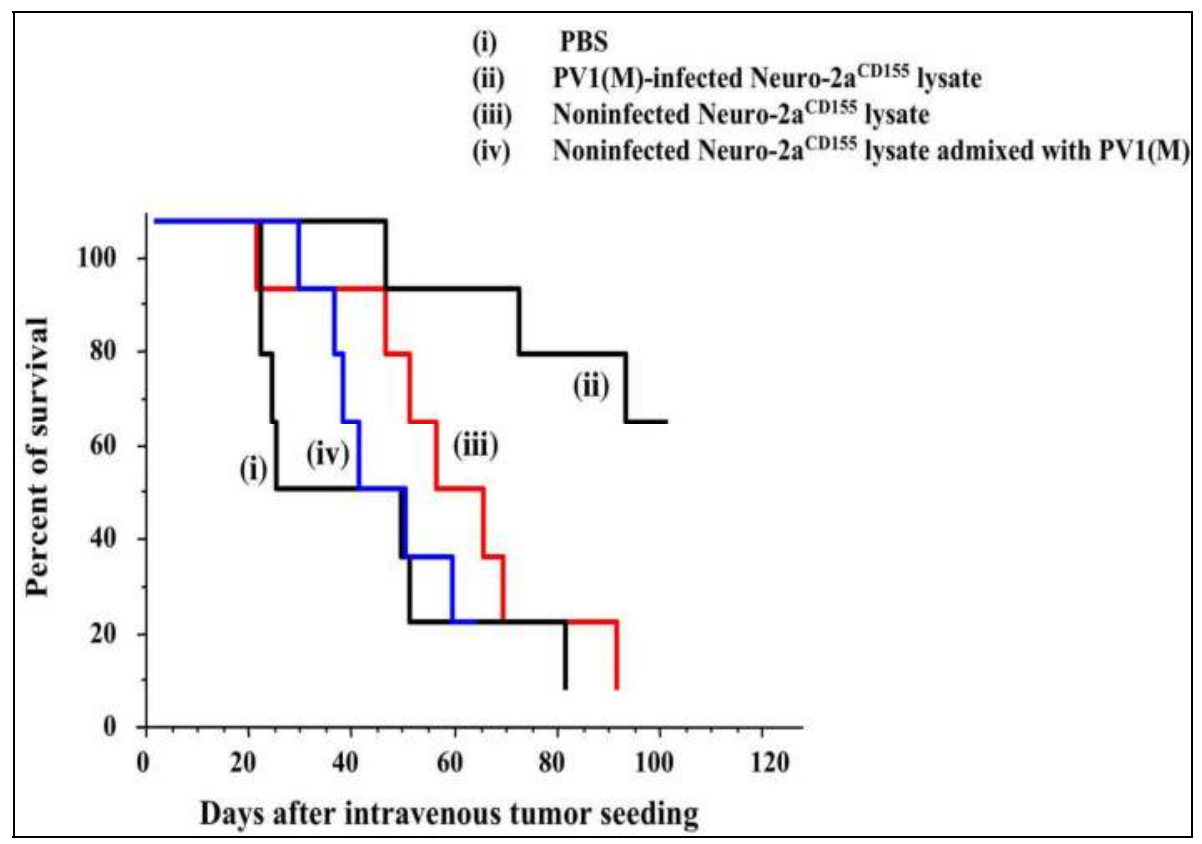

Fig. 3. Survival of mice inoculated withNeuro-2aCD155. Before challenge, mice were vaccinated with different lysates or PBS. Mice were observed every day and survival was plotted using a Kaplan-Meier survival curve.

We ruled out the possibility that protection effect seen in mice immunized with PV-infected Neuro-2aCD155 lysate is due to a cytolitic effect by an ongoing poliovirus infection after lysate injection. Our assertion is based in the following facts: i) no poliovirus were isolated from the lung, liver, spleen, brain and spinal cord of mice at the time of tumor challenge, i.e., 21 days after vaccination with homogenates prepared from PV1(M)-infected Neuro2aCD155 cells or noninfectedNeuro-2aCD155 admixed with poliovirus, ii) No protection was induced by noninfected Neuro-2aCD155 admixed with poliovirus, and iii) all mice are vaccinated with different lysates or previously immunized against poliovirus. Altogether, 
our results clearly suggest that in vitro infection of neuroblastoma cells turn these cells into a potent tumor immunogen.

It has long been assumed that most therapeutic agents kill tumor cells through apoptosis. Notably, apoptosis has been considered to be a non-immunogenic or even a tolerogenic cell death mechanism as opposed to necrosis (an immunogenic cell death). However, depending on the cell death inducer, tumor cells can become highly immunogenic and induce a potent antitumor response in vivo (Zitvogel et al., 2006). Furthermore, there is now persuasive evidence that cell death can trigger an immune response only if the dying cells emit 'eatme', 'danger' and 'killing' signals that mediate their efficient phagocytosis by dendritic cells (DC's) and the maturation of DCs (Blachere et al., 2005; Casares et al., 2005; Kepp et al., 2009; Melcher et al., 1998; Sauter et al., 2000).

DCs are the most important professional antigen-presenting cells and play a central role in initiating innate and adaptive immune response against tumor associate antigens (TAA). Antigen presentation by immature DCs (iDCs), associated with a lack of costimulation, induces tolerance. A number of molecules released from dying cells have been identified to elicit immune signaling during immunogenic cell death.

These include, among others, high mobility group box 1 (HMGB1, also known as amphoterin), purine metabolites (uric acid), calreticulin (CRT), and heat shock proteins (HSP) (Freedman et al., 1988; Obeid et al., 2007a; Shi et al., 2003; Udono \& Srivastava, 1994). Induction of HSP is one of the earliest indications of cellular stress following infection with both RNA and DNA viruses (Asea, 2007; Liu et al., 2008). HSPs have been found to play key roles in the stimulation of the immune system when located on the plasma membrane or in the extracellular space (Udono \& Srivastava, 1994). These proteins can promote tumor antigen cross-priming by binding to DC (Schild et al., 1999; Srivastava et al., 1998). Moreover, HSP 70 and 90 expressions act as "eat me" signals and enhance phagocytosis and maturation of DC (Binder \& Srivastava, 2004; Lehner et al., 2004). CRT, another 'eat me' signal, is located in the lumen of the endoplasmic reticulum (ER) (Obeid et al., 2007a). Upon stress, CRT is translocated and exposed on the outer leaflet of cells during the early phase of cell death (Obeid et al., 2007a, 2007b). The exposure of CRT dictates the immunogenicity of tumor cells death because exposed CRT help the engulfment of dying tumor cells by DC (Obeid et al., 2007a). Investigators have previously identified uric acid as a novel endogenous danger signal capable of alerting the immune system (Shi et al., 2003). Injury cells rapidly degrade their DNA and RNA and release uric acid that activates DCs. Another signal molecule is HMGB1, which is loosely bound to chromatin and is referred to as 'danger signal' or alarmin (27). Dying cells release this molecule massively in the extracellular environment (Scaffidi et al., 2002). Extracellular HGMB1 induces functional maturation of DCs and acts as immune adjuvant for soluble and particulate antigens (Dumitriu et al., 2005; Rovere-Querini et al., 2004).

Until now, most of the identified inducers of immunogenic cell death of tumors cells are chemotherapheutics (Ulrich et al., 2008). The potent antitumor response elicited by virotherapy, observed by us and other investigators, clearly suggests that viruses are in vivo inducers of immunogenic death of tumor cells. Moreover, our finding that inoculation of PV-infected neuroblastoma lysate protects against live tumor challenge indicates that poliovirus is also an in vitro inducer of immunogenic death. Interestingly, necrosis by freeze-thawing is also considered as an immunological cell death (Ulrich et al., 2008). However, we observed that immunization with freeze-thawed noninfected neuroblastoma 
lysate, as opposed to the PV-infected lysate, did not protect against live tumor challenge. This result underscores the capacity of poliovirus to trigger the release of danger signals from tumor cells, which in turn it could induce an antitumor response.

Significantly, cells infected with encephalomyocarditis virus, a picornavirus as polio, have been shown to be effective at presenting nonviral antigens for cross-priming of DCs in vivo (Schulz et al., 2005). Viral lysates (called oncolysate) have been used in the past to vaccinate human against cancer (Sinkovics \& Horvth, 2006). Those few trials have shown some degrees of success, but results have been ambiguous (Cassel \& Murray, 1992; Freedman et al., 1988; Murray et al., 1977).

Remarkably, treatment with viral oncolysates showed better overall survival than radio-and chemo-therapy, probably because of the harmful effects of conventional therapies has on the immune system (White et al., 2002). On the other hand, using live viruses in humans for the treatment of cancer comes with some drawbacks. Inoculation of a virus, mainly a high dose, could elicit an unwanted inflammatory reaction, or cause an opportunistic infection or an unexpected complication (Bell et al., 2003; Kirn et al., 2001). Furthermore, the majority of human population is immune to several of the potential therapy viruses (Bell et al., 2003). Therefore, innate and pre-existing immunity may inactive the oncolytic virus which limits its use in systemic virotherapy (Ikeda et al., 1999; Kirn et al., 2001). Tumor vaccine therapy using virus lysate may overcome some of these hurdles. Viral oncolysate can be prepared with nonpathogenic virus without losing its tumor immunogenicity. Hypothetically, inactivation of the live virus present in the viral oncolysate should not affect the antitumor response induced by viral oncolysate. Finally, immunotherapy with viral oncolysate can be more effective than tumor virotherapy in controlling minimal residual and metastatic diseases states, thereby preventing or prolonging the time of recurrence.

\section{Hypothesis and future studies}

We hypothesize that in vitro poliovirus infection of neuroblastoma cells induces an immunogenic tumor cell death through a massive upregulation of endogenus alarm signals. We entertain the idea that the main alarm signals induced by poliovirus infection of tumor cells are CRT, HSP 70 and 90, uric acid and HMGB1, which in turn mediate DC activation. Therefore, we also hypothesize that PV-infected neuroblastoma lysate induces an effective DC maturation and tumor antigen cross-presentation. Finally, we postulate that immunization with PV-infected neuroblastoma lysate generates a systemic and potent anti tumor response that will eradicate established tumors and will confer a long-lasting tumor immunity.

Overall, there is enough information to expect that the immunization with polio lysate might represent a new treatment for neuroblastoma. However, the antitumor response induced by polio oncolysate remains largely uncharacterized. Therefore, a detailed knowledge of the immune response and therapeutic protection elicited by polio-infected neuroblastoma lysates is needed. Specifically, future studies should aim to determine:

- Aim I. If poliovirus infection of neuroblastoma cells induces upregulation, translocation and release of endogenous danger signals.

- Aim II. If polio-infected neuroblastoma lysates can induce DC maturation and presentation of tumor-derived antigens

- $\quad$ Aim III. Whether immunization with polio-infected neuroblastoma lysates can induce a systemic immune response capable of eradicating established cancer and stimulating a long-lasting anti-tumor immunity 


\section{Aim I}

Rationale

Tumors evoke mechanism to induce immune tolerance. In this context, tumor cells are nonimmunogenic and their death will not stimulate an antitumor response. On the other hand, tumor cells can be stressed by multiple stimuli and may promote membrane expression or release of endogenous danger signals. The upregulation of these signals will turn nonimmunogenic tumor cells into immunogenic tumor cells, and facilitate immune recognition and final elimination of the stressed tumor cells. It has been shown that chemotherapeutic agents activates pro-apoptotic promoter BAX, which in turn induce translocation and exposure of two potent danger signals, CRT and HMGB1 (Kepp et al., 2009; Krynetskaia et al., 2008). Interestingly, poliovirus infection activates BAX in neuroblastoma cells (Autret et al., 2007). It is tempting to speculate that different inducers of immunogenic cell death activate common pathways to upregulate, translocate and release endogenous warning molecules. Thus, we postulate that poliovirus infection of neuroblastoma cells induce the upregulation and translocation of CRT, uric acid, HSP 70 and 90, and HMGB1. We also hypothesize that signal-inducing capacity of poliovirus depends on virus strain and infectious dose.

Approach.

Neuroblastoma cells will be infected with different poliovirus strains at different multiplicity of infection (MOI). At different time points after infection, the presence of CRT, uric acid, HSP 70 and 90, and HMGB1 in virus-infected cells and/or their supernatants will be determined. It also important to determine apoptosis/death of infected cells by Annexin V/PI test.

Expected results and alternatives.

Based in our previous results (see above in point 3), we think that poliovirus is a potent inducer of immunogenic cell death. Therefore, it is expected that infection of neuroblastoma cells will lead to surface exposure of CRTL, translocation of HMGB1 from nucleus to cytoplasm of infected cells followed by release into cell culture medium. We also anticipate a rapid increase in the expression of inducible HSP70 and HSP 90 and in the concentration of uric acid within cells and in supernatant of polio-infected cells.

With this approach, we should be able to determine the kinetic of different danger signal expressions induced by poliovirus before overt CPE is developed. We should also be capable of correlating the kinetic of danger signals and apoptotic or necrotic profile of the virus-infected tumor cells. Finally, we speculate that there are differences between different poliovirus strains in their capacity to induce upregulation of danger signals, and with our experimental approach we should be able to determine these differences. It is possible that the endogenous danger signals that we are going to analyze are poorly or not at all induced by poliovirus. In this case, we will look for other potential immunogenic determinants of dying tumor cells such as NKG2D ligands, RNA, HSP27, DNA, PTX3, IL-1 $\beta$. Alternatively, proteomic analyses can be done to identify new putative "alarming" signals induced by poliovirus infection.

The way in which exogenous insults kill a tumor cell is likely to be a key determinant of the interaction of dying cells with the immune system and whether this interaction will lead to an immune response. Here we will define if poliovirus infection of neuroblastoma cells induces an immunogenic cell death through upregulation and translocation of endogenous danger signals. cell death through upregulation and translocation of endogenous danger signals. 


\section{Aim II}

Rationale

In response to various cell death associated stimuli, Dcs have been shown to play a central role in the recognition of apoptotic cell death and in the initiation of an immune response, Only when danger signals are correctly emitted by dying cells, in response to a stimulus, and perceived by DC, an immune response is elicited.

On the other hand, pathogen induced cell death can be immunogenic and hence stimulate an immune response against antigens that derive from dying cells and are presented by dendritic cells (DCs). Here we postulate that poliovirus infection of neuroblastoma cells induces an immunogenic death of these tumor cells. Therefore, lysate from these cells contain several immunogenic (danger) signals and tumor associated antigens that will induce DC maturation and tumor antigen-presentation.

Approach

Initially, mouse DC will be treated with polio oncolysates to determine whether these oncolysate could stimulate DC maturation. To assess DC activation by different viral lysates, phenotypic DC maturation and production of cytokines will be measured. To address whether the DC response to viral lysate could impact on downstream pathways of anti-tumor immune response, we will test stimulation of splenocytes from neuroblastoma-challenged mice via presentation by viral lysate-actived DC. As markers of splenocytes activation, IL 2, 4, 10 and IFN- $\gamma$ release and cytotoxic activity will be determined.

Expected results and alternatives. As mentioned in Aim 1, poliovirus infection of neuroblastoma cells provokes an immunogenic cell death. Therefore, we expect that the interaction between polio-infected neuroblastoma lysate and iDCs will result in DC maturation, allowing the DCs to activate relevant cell mediated immunity against tumor cells. Our experimental approach will allow us to determine the ability of viral oncolysate pulsed DC to present tumor and viral antigens to primed T cells. Moreover, we expect that oncolysate-pulsed DCs will be able to prime naïve splenocytes against tumor antigens. In line with our theory, we speculate that wild type poliovirus is a stronger inducer of immunogenic cell death than the other strains used in this study. Thus, PV1(M)-oncolysate will induce a stronger activation of DC than those stimulated by the polio replicon or the neuroattenuated polio oncolysate. However, we think that DCs will mature and acquire the ability of presenting tumor antigens upon stimulation with polio replicon oncolysate or the neuroattenuated polio oncolysate.

It might be possible that the activation signals provided by oncolysate induce a poor maturation of DCs. To solve this problem, we can concentrate the oncolysates and test their capacity to induce DC maturation. Alternatively, we can mix oncolysate with small amounts of LPS (10-50 pg) to boost DC maturation. It is expected that polio oncolysate has a high concentration of poliovirus proteins. Therefore, DCs may preferentially present poliovirus antigens. In this case, oncolysate-pulsed DC will induce a poor antitumor response. We propose to increase the amount of tumor antigens presented to DCs. For this purpose, we will use cell membrane isolated from neuroblastoma cells as source of tumor antigens. After concentration, cell membranes will be mixed with oncolysate and the mixture will be used to pulse DCs. 


\section{Aim III}

Rationale

Unfortunately, the prognosis for many children diagnosed with neuroblastoma is poor despite aggressive surgical resection and simultaneous radiochemotherapy regimens. Moreover, the frequency of relapse and the subsequent failure of further treatment have created the need to develop non-toxic and more effective treatments. Immunotherapy has the theoretical appeal that tumor-reactive lymphocyte may seek and eliminate tumor cells with greater accuracy than conventional therapy. A limiting impediment to successful immunotherapeutic treatment is the stimulation of adequate tumor antigen-specific effector cells. To attain this, tumor-associated antigens should be processed by antigen presenting cells (APCs), and presented to T cells along with enough costimulatory signals to avoid tolerance. Our previous results showed that polio oncolysate is able to prime an antineuroblastoma response. This result indicate that viral oncolysate contain tumor associated antigens and immunoadjuvant molecules which activate the immune system to elicit a prophylatic tumor response. Based on this finding, we propose to continue our studies and determine if immunization with polio-infected neuroblastoma oncolysate could evoke a tumor-specific immunity capable of eradicating established neuroblastoma as well as maintaining immunological memory. On the other hand, viral oncolysate contain infectious virus. Therefore, inoculation of viral oncolysate may cause severe complications. To circumvent this problem, we also propose to obtain viral oncolysate from neuroblastoma cells infected with polio replicon. These RNA-based vectors are generated by providing the capsid proteins in trans, they can undergo only a single round of replication in the infected cell and they are genetically incapable of producing infectious virus.

Therefore, we will also determine the capacity of noninfectious poliovirus replicon-infected lysate to induce a therapeutic effect against established tumor.

Approach.

We will establish hepatic and subcutaneous Neuro-2aCD155 tumors in polio-immunized CD155 tg A/J. Ten days after tumor cell inoculation, animals will be vaccinated intraperitonally (i.p) or intramuscuraly (i.m) with neuroblastoma lysates prepared from tumor cells infected with wild type PV1 (M), neuroattenuated A133GmonocrePV or propagation-defective poliovirus (poliovirus replicon). Control mice will be inoculated with noninfected neuroblastoma lysates or PBS. To determine long-lasting anti tumor immunity evoked by oncolysate vaccination, mice previously cured with any experimental treatment described above or 6 months after immunization with different lysates will be challenged i.v. or s.c with neuroblastoma cells. Protection response to each experimental therapy will be measured by survival rates and tumor growth. Splenocytes and sera from each experimental group will be obtained to test tumor-and virus specific immunity.

Expected results and alternatives. First, we expect to obtain a comprehensive characterization of tumor-specific and virus-specific induced by in vivo vaccination with poliovirus oncolysate. We think that in vivo administration of polio oncolysates will mediate a strong therapeutic benefit and eliminate or slow significantly tumor growth, preferentially on established liver metastases. Based on our previous results, we anticipate that in vivo vaccination with polio oncolysate will induce a robust memory response. Since tumor immunogenicity of polio oncolysates might be different depending on poliovirus strain used for their preparation, we expect to see differences in the therapeutic effect induced by each of the oncolysate tested. There is concern that immunity induced by 
repetitive inoculation of viral oncolysate will be biased towards a viral immune response. Our experimental approach will allow us to determine the tumor-specific and virus-specific and therapeutic effect induce by in vivo immunization with oncolysate. Correlation of these data should identify whether the biased response affects the effectiveness of immunotherapeutic treatment.

It is possible, although unlikely, that in vivo vaccination with oncolysate will induce a poor anti-tumor response. If we detect that the reason of this poor anti-tumor response is due to oncolysate vaccination bias the immune response to virus, we will increase the tumor antigens in the oncolysate as described in Aim 2. Another possibility for a poor antit-tumor response is a low adjuvanticity of viral oncolysate in vivo. In this case, we propose to mix viral oncolysate with $\mathrm{CpG}$ oligodeoxynucleotides. $\mathrm{CpG}$ has been successful used as an adjuvant in other mouse models of immunotherapy for treatment of several tumors. Alternatively, we may improve the immune response against the tumor by combining frequency, timing, dose and route of administration of viral oncolysate.

\section{Conclusion}

In the current state of the art, it is likely that virotherapy using attenuated poliovirus will be capable of eradicating neuroblastoma when used in combination with other therapies. Moreover, immunotherapy with PV oncolysate alone or in combination with virotherapy can be effective in controlling minimal residual and metastatic diseases states, thereby preventing recurrence or prolonging the time of recurrence in patient suffering from neuroblastoma. Therefore, we think that our data and the directions of future studies presented here will lead to practical applications of attenuated poliovirus and polio oncolysate for the treatment of neuroblastoma

\section{References}

Aghi, M., \& Martuza, R. (2005). Oncolytic viral therapies: the clinical experience. Oncogene, 24, pp. $7802-7816$

Asada, T. Treatment of human cancer with mumps virus. (1974). Cancer, 34, pp. 1907-1928

Asea A. Mechanisms of HSP72 release. (2007). J Biosci, 32, pp. 579-84

Autret, A., Martin-Latil, S., Mousson, L., Wirotius, A., Petit, F, Arnoult, D., Colbère-Garapin, F., Estaquier, J., \& Blondel, B. (2007). Poliovirus induces Bax-dependent cell death mediated by c-Jun NH2-terminal kinase. J Virol, 81, pp. 7504-7516

Bell, C., Lichty, B., \& Stojdl, D. Getting oncolytic virus therapies off the ground. (2003). Cancer Cell,4, pp. 7-11

Binder, R., \& Srivastava, P. (2004). Essential role of CD91 in re-presentation of gp96chaperoned peptides. Proc Natl Acad Sci USA, 101, pp. 6128-6133

Bischoff, J., Kirn, D., Williams, A., Heise, C., Horn, S., Muna, M., Ng, L., Nye, J., SampsonJohannes, A., Fattaey, A., \& McCormick, F. (1996). An adenovirus mutant that replicates selectively in p53-deficient human tumor cells. Science, 274, pp. 373-376

Blachère, N., Darnell, R., \& Albert M. (2005). Apoptotic cells deliver processed antigen to dendritic cells for cross-presentation PLoS Biol 3:e185.

Brodeur, G., \& Maris, J. (2006). Neuroblastoma. In: Pizzo PA, Poplack DG (eds) Principles and practice of pediatric oncology. 5th edn. Lippincott Williams and Wilkins, Philadelphia, pp 933-970 
Casares, N., Pequignot, M., Tesniere, A., Ghiringhelli, F., Roux, S., Chaput, N., Schmitt, E., Hamai, A., Hervas-Stubbs, S., Obeid, M., Coutant, F., Métivier, D., Pichard, E., Aucouturier, P., Pierron, G., Garrido C., Zitvogel, L., \& Kroemer, G. (2005). Caspase dependent immunogenicity of doxorubicin- induced tumor cell death. J Exp Med, 202, pp. 1691-1701

Cassel, W., \& Murray, D. (1992). A ten-year follow-up on stage II malignant melanoma patients treated postsurgically with Newcastle disease virus oncolysate. Med Oncol Tumor Pharmacother, 9, pp. 169-171.

Cello, J., Paul, A., \& Wimmer, E.. (2002). Chemical synthesis of poliovirus cDNA: generation of infectious virus in the absence of natural template. Science, 297, pp. 1016-1018

Cello, J., Toyoda, H., Dejesus, N., Dobrikova, E., Gromeier, M., \& Wimmer, E. (2008). Growth phenotypes and biosafety profiles in poliovirus-receptor transgenic mice of recombinant oncolytic polio/human rhinoviruses. J Med Virol, 80, pp. 352-359

Coffey, M., Strong, J., Forsyth, P., \& Lee, P. (1998). Reovirus therapy of tumors with activated ras pathway, Science, 282, pp. 1332-1334.

DePace, N. (1912). Rabies virus treatment of cervical cancer. Ginecologia, 9, pp. 82

Decker, T., \& Lohmann-Matthes, M. (1988). A quick and simple method for the quantitation of lactate dehydrogenase release in measurements of cellular cytotoxicity and tumor necrosis factor (TNF) activity. J Immunol Methods, 115, pp. 61-69

De Jesus, N., Franco, D., Paul, A., Wimmer, E., \& Cello, J. (2005). Mutation of a single conserved nucleotide between the cloverleaf and internal ribosome entry site attenuates poliovirus neurovirulence. J Virol 79, pp. 14235-14243

Diaz, R., Galivo, F., Kottke, T., Wongthida, P., Qiao, J., Thompson, J., Valdes, M., Barber, G., \& Vile, R. (2007). Oncolytic immunovirotherapy for melanoma using vesicular stomatitis virus. Cancer Res, 67, pp. 2840-2848

Dumitriu, I., Baruah, P., Manfredi A., Bianchi, M., \& Rovere-Querini, P. (2005). HMGB1: guiding immunity from within. Trends Immunol, 26, pp. 381-387

Freedman, R., Edwards, C., Bowen, J., Lotzova, E., Katz, R., Lewis, E., Atkinson, N., \& Carsetti, R. (1988). Viral oncolysates in patients with advanced ovarian cancer. Gynecol Oncol, 29, pp. 337-347

Gao, R.N., I. G. Levy, W. G. Woods, B. A. Coombs, L. A. Gaudette, and G. B. Hill. 1997. Incidence and mortality of neuroblastoma in Canada compared with other childhood cancers. Cancer Causes and Control, 8, pp. 745-754

Greiner, S., Humrich, J., Thuman, P., Sauter, B., Schuler, G., \& Jenne, L. (2006). The highly attenuated vaccinia virus strain modified virus Ankara induces apoptosis in melanoma cells and allows bystander dendritic cells to generate apotent antitumoral immunity. Clin Exp Immunol, 146, pp. 344-353

Gromeier, M., Alexander, L., \& Wimmer, E. (1996). Internal ribosomal entry site substitution eliminatesneurovirulence in intergeneric poliovirus recombinants. Proc Natl Acad Sci U S A, 93, pp. 2370-2375

Gromeier, M., Bossert, B., Arita, M., Nomoto, A., \& Wimmer, E. (1999). Dual stem loops within the poliovirus internal ribosomal entry site control neurovirulence. J Virol, 73, pp. 958-964

Gromeier, M., Lachmann, S., Rosenfeld, M., Gutin, P., \& Wimmer, E. (2000). Intergeneric poliovirus recombinants for the treatment of malignant glioma. Proc Natl Acad Sci U $S$ A, 97, pp. 6803-6808 
Gurney, J., Ross, J., Wall, D., Bleyer, W., Severson, R., \& Robison, L. (1997). Infant cancer in the U.S.: histology-specific incidence and trends, 1973 to $1992 . J$ PediatricHematology/Oncology, 19, pp. 428-432

Hammond, A., Plemper, R., Zhang, J., Schneider, U., Russell, S., \& Cattaneo, R. (2001). Single-chain antibody displayed on a recombinant measles virus confers entry through the tumor-associated carcinoembryonic antigen. J Virol, 75, pp. 2087-2096

Hallenbeck, P., Chang, Y., Hay, C., Golightly, D., Stewart, D., Lin, J., Phipps, S., \& Chiang, Y. (1999). A novel tumor-specific replication-restricted adenoviral vector for gene therapy of hepatocellular carcinoma. Hum Gene Ther, 10, pp. 1721-1733

Huebner, R., Rowe, W., Schatten, W., Smith. R., \& Thomas, L. (1956). Studies on the use of viruses in the treatment of carcinoma of the cervix. Cancer, 9, pp. 1211-1218

Ikeda, K., Ichikawa, T., Wakimoto, H., Silver, J., Deisboeck, T., Finkelstein, D., Harsh G., Louis, D., Bartus, R., Hochberg F., \& Chiocca, E. (1999). Oncolytic virus therapy of multiple tumors in the brain requires suppression of innate and elicited antiviral responses. Nat Med, 5, pp. 881-887

Kepp, O., Senovilla, L., Galluzzi, L., Panaretakis, T., Tesniere, A., Schlemmer, F., Madeo, F., Zitvogel, L., \& Kroemer, G.. (2009). Viral subversion of immunogenic cell death. Cell Cycle, 8, pp. 860-869

Kirn, D., Martuza, R., \& Zwiebel, J. (2001). Replication-selective virotherapy for cancer: Biological principles, risk management and future directions. Nat Med, 7, pp. 781-787

Kottke, T., Diaz, R., Kaluza, K., Pulido, J., Galivo, F., Wongthida, P., Thompson, J., Willmon, C., Barber, G., Chester, J., Selby, P., Strome, S., Harrington, K., Melcher, A., \& Vile, R. (2008). Use of biological therapy to enhance both virotherapy and adoptive T-cell therapy for cancer. Mol Ther, 16, pp. 1910-1918

Krynetskaia, N., Xie, H., Vucetic, S., Obradovic, Z., \& Krynetskiy, E. (2008). High mobility group protein B1 is an activator of apoptotic response to antimetabolite drugs. Mol Pharmacol, 73, pp. 260-269

Kumar, S., Gao, L., Yeagy, B., \& Reid, T. (2008). Virus combinations and chemotherapy for the treatment of human cancers. Curr Opin Mol Ther, 10, pp. 371-379

Maris, J., \& Matthay, K. (1999). Molecular biology of neuroblastoma, J Clin Oncol, 17, pp. 2264-2279

Martuza, R., Malick, A., Markert, J., Ruffner, K., \& Coen, D. (1991). Experimental therapy of human glioma by means of a genetically engineered virus mutant. Science, 252, pp. 854-856

Mastrangelo, M., Eisenlohr, L., Gomella, L., \& Lattime, E. (2000). Poxvirus vectors: Orphaned and underappreciated. J Clin Invest, 105, pp. 1031-1034

Matthay, K., Villablanca, J., Seeger, R., Stram, D., Harris R., Ramsay N., Swift, P., Shimada, H., Black, C., Brodeur, G., Gerbing, R., \& Reynolds, C. (1999). Treatment of highrisk neuroblastoma with intensive chemotherapy, radiotherapy, autologous bone marrow transplantation, and 13-cis-retinoic acid: a Children's Cancer Group study. N Engl J Med, 341, pp. 1165-1173

Matthay, K., Reynolds, C., Seeger, R., Shimada, H., Adkins, E., Haas-Kogan, D., Gerbing, R., London, W., \& Villablanca, J. (2009). Long-term results for children with high-risk neuroblastoma treated on a randomized trial of myeloablative therapy followed by 13-cis-retinoic acid: a Children's Oncology Group study. J Clin Oncol, 27, pp. 10071013 
Melcher, A., Todryk, S., Hardwick, N., Ford, M., Jacobson, M., \& Vile, R. (1998). Tumor immunogenicity is determined by the mechanism of cell death via induction of heat shock protein expression. Nat Med, 4, pp. 581-587

Miyatake, S., Iyer, A., Martuza, R., \& Rabkin, S. (1997). Transcriptional targeting of herpes simplex virus for cell-specific replication. J Virol, 71, pp. 5124-1532

Moehler, M., Zeidler, M., Wilsberg, V., Cornelis, J., Woelfel, T., Rommelaere J., Galle P., \& Heike, M. (2005). Parvovirus H-1-induced tumor cell death enhances human immune response in vitro via increased phagocytosis, maturation, and crosspresentation by dendritic cells. Hum Gene Ther, 16, pp. 996- 1005

Mohr, I. (2005). To replicate or not to replicate: achieving selective oncolytic virus replication in cancer cells through translational control. Oncogene, 24, pp. 7697-709

Mueller, S., \& Wimmer, E. (2003). Recruitment of nectin-3 to cell-cell junctions through transheterophilic interaction with CD155, a vitronectin and poliovirus receptor that localizes to \{alpha\}(v)B3 integrin-containing membrane microdomains. J Biol Chem, 278, pp. 31251-31260

Mueller, S., Wimmer, E., \& Cello, J. (2005). Poliovirus and poliomyelitis: a tale of guts, brains, and an accidental event. Virus Res, 111, pp. 175-193

Murray, D., Cassel, W., Torbin, A., Olkowski, Z., \& Moore, M. (1977). Viral oncolysate in the management of malignant melanoma. II. Clinical studies. Cancer, 40, pp. 680-686

Nandi, S., Ulasov, I., Tyler, M., Sugihara, A., Molinero, L., Han, Y., Zhu, Z., \& Lesniak, M. (2008). Low-dose radiation enhances survivin-mediated virotherapy against malignant glioma stem cells. Cancer Res, 68, pp. 5778-5784

Newman, W., \& Southam, C. (1954). Virus treatment in advanced cancer; a pathological study of fifty- seven cases. Cancer, 7, pp. 106-118

Leaf, C. (2004). Why we're losing the war on cancer and how to win it. Fortune, pp. 76-92

Lehner, T., Wang, Y., Whittall, T., McGowan, E., Kelly, C., \& Singh, M. (2004). Functional domains of HSP70 stimulate generation of cytokines and chemokines, maturation of dendritic cells and adjuvanticity. Biochem Soc Trans, 32, pp. 629-632

Li, H., Dutuor, A., Fu, X., \& Zhang, X. (2007a). Induction of strong antitumor immunity by an HSV-2-based oncolytic virus in a murine mammary tumor model. J Gene Med, 9, pp. 161-169

Li, H., Dutuor, A, Tao, L., Fu, X., \& Zhang, X. (2007b). Virotherapy with a type 2 herpes simplex virus derived oncolytic virus induces potent antitumor immunity against neuroblastoma. Clin Cancer Res, 13, pp. 316-322

Liu, C., Erlichman, C., McDonald, C., Ingle, J., Zollman, P., Iankov, I., Russell, S., \& Galanis, E. (2008). Heat shock protein inhibitors increase the efficacy of measles virotherapy. Gene Ther, 15, pp. 1024-1034

Lorence, R., Rood, P., \& Kelley, K. (1988). Newcastle disease virus as an antineoplastic agent: Induction of tumor necrosis factor-alpha and augmentation of its cytotoxicity. J Natl Cancer Inst, 80, pp. 1305-1312

Obeid, M., Tesniere, A., Ghiringhelli, F., Fimia, G., Apetoh, L., Perfettini, J., Castedo, M., Mignot, G., Panaretakis, T., Casares, N., Métivier , D., Larochette, N., van Endert, P., Ciccosanti, F., Piacentini, M., Zitvogel, L., \& G. Kroemer. (2007a). Calreticulin exposure dictates the immunogenicity of cancer cell death. Nat Med, 13, pp. 54-61

Obeid, M., Panaretakis, T., Joza, N., Tufi, R., Tesniere, A., van Endert, P., Zitvogel, L., \& Kroemer, G. (2007b). Calreticulin exposure is required for the immunogenicity of 
gamma-irradiation and UVC light induced apoptosis. Cell Death Differ, 14, pp. 18481850

Ochiai, H., Moore, S., Archer, G., Okamura, T., Chewning, T., Marks, J., Sampson, J., \& Gromeier, M. (2004). Treatment of intracerebral neoplasia and neoplastic meningitis with regional delivery of oncolytic recombinant poliovirus. Clin Cancer Res, 10, pp. 4831-4838

Ochiai, H., Campbell, S., Archer, G., Chewning, T., Dragunsky, E., Ivanov, A., Gromeier, M., \& Sampson, J. (2006). Targeted therapy for glioblastoma multiforme neoplastic meningitis with intrathecal delivery of an oncolytic recombinant poliovirus. Clin Cancer Res, 12, pp. 1349-1354

Okuno, Y., Asada, T., Yamanishi, K., Otsuka, T., Takahashi, M., Tanioka, T., Aoyama, H., Fukui, O., Matsumoto, K., Uemura, F., \& Wada, A. (1978). Studies on the use of mumps virus for treatment of human cancer. Biken J, 21, pp. 37-49

O'Shea, C. (2005). Viruses- seeking and destroying the tumor program. Oncogene, 24, pp. $7640-7655$

Pack, G. (1950). Note on the experimental use of rabies vaccine for melanomatosis. AMA Arch Derm Syphilol, 62, pp. 694-695

Parato, K. A., D. Senger, P. A. Forsyth, and J. C. Bell. (2005). Recent progress in the battle between oncolytic viruses and tumours. Nat Rev Cancer, 5, pp. 965-976

Park, J., Eggert, A., \& Caron, H. (2008). Neuroblastoma: Biology, Prognosis and Treatment. Pediatr Clin North Am, 55, pp. 97-120

Paul, A. (2002). Possible unifying mechanism of picornavirus genome replication. In: Semler BL, Wimmer E, editors. Molecular biology of picornaviruses. Washington (DC): ASM Press, p. 227-246

Qiao, J., Kottke, T., Willmon, C., Galivo, F., Wongthida, P., Diaz, R., Thompson, J., Ryno, P., Barber, G., Chester, J., Selby, P., Harrington, K., Melcher, A., \& Vile, R. (2008). Purging metastases in lymphoid organs using a combination of antigen nonspecific adoptive $\mathrm{T}$ cell therapy, oncolytic virotherapy and immunotherapy. Nat Med, 14, pp. 37-44

Ries, L., Eisner, M., Kosary, C., Hankey, B., Miller, B., \& Clegg, L. (2005). SEER Cancer Statistics Review, 1975-2002. Bethesda, MD: National Cancer Institute

Rovere-Querini, P., Capobianco, A., Scaffidi, P., Valentinis, B., Catalanotti, F., Giazzon, M., Dumitriu, I., Muller, S., Iannacone, M., Traversari, C., Bianchi, M., \& A. Manfredi, A. (2004). HMGB1 is an endogenous immune adjuvant released by necrotic cells. EMBO Rep, 5, pp. 825-830

Sauter, B., Albert, M., Francisco, L., Larsson, M., Somersan, S., \& Bhardwaj, N. (2000). Consequences of cell death: exposure to necrotic tumor cells, but not primary tissue cells or apoptotic cells, induces the maturation of immunostimulatory dendritic cells. J Exp Med, 191, pp. 423-434

Scaffidi, P., Misteli, T., \& Bianchi, M. (2002). Release of chromatin protein HMGB1 by necrotic cells triggers inflammation. Nature, 418, pp. 191-195

Schild, H., Arnold-Schild, D., Lammert, E., \& Rammensee, H. (1999). Stress proteins and immunity mediated by cytotoxic T lymphocytes. Curr Opin Immunol, 11, pp. 109-113

Schulz, O., Diebold, S., Chen, M., Näslund, T., Nolte, M., Alexopoulou, L., Azuma, Y., Flavell, R., Liljeström, P., \& Reis e Sousa, C. (2005). Toll-like receptor 3 promotes cross-priming to virus infected cells. Nature, 433, pp. 887-892 
Shi, Y., Evans, J., \& Rock, K. (2003). Molecular identification of a danger signal that alerts the immune system to dying cells. Nature, 425, pp. 516-521

Sinkovics, J., \& Horvath, J. (1993). New developments in the virus therapy of cancer: a historical review. Intervirology, 36, pp. 193-214

Sinkovics, J., \& Horvath, J. (2006). Evidence accumulating in support of cancer vaccines combined with chemotherapy: a pragmatic review of past and present efforts. Int $J$ Oncol, 29, pp. 765-777

Spix, C., Pastore, G., Sankila, R., Stiller, C., \& Steliarova-Foucher, E. (2006). Neuroblastoma incidence and survival in European children (1978-1997): report from the Automated Childhood Cancer Information System project. European J Cancer, 42, pp. 2081-2091

Southam, C., \& Moore, A. (1952). Clinical studies of viruses as antineoplastic agents with particular reference to Egypt 101 virus. Cancer, 5, pp. 1025-1034

Southam, C., Hilleman, M., \& Werner, J. (1956). Pathogenicity and oncolytic capacity of RI virus strain RI-67 in man. J. Lab. Clin. Med., 47, pp. 573-582

Srivastava, P., Menoret, A., Basu, S., Binder, R., \& McQuade, K. (1998). Heat shock proteins come of age: primitive functions acquire new roles in an adaptive world. Immunity, 8, pp. 657-665

Stojdl, D., Lichty, B., Knowles, S., Marius, R., Atkins, H., Sonenberg, N., \& Bell, J. (2000). Exploiting tumor-

specific defects in the interferon pathway with a previously unknown oncolytic virus. Nature Med, 6, pp. 821-825

Toda, M., Rabkin, S., Kojima, H., \& L. Martuza, R. (1999). Herpes simplex virus as an in situ cancer vaccine for the induction of specific anti-tumor immunity. Hum Gene Ther, 10, pp. 385-393

Toyoda, H., Ido, M., Hayashi, T., Gabazza, E., Suzuki, K., Kisenge, R., Kang, J., Hori, H., \& Komada, Y. (2004). Experimental treatment of human neuroblastoma using liveattenuated poliovirus. Int J Oncol, 24, pp. 49-58.

Toyoda, H., Yin, J., Mueller, S., Wimmer, E., \& Cello, J. (2007). Oncolytic treatment and cure of neuroblastoma by a novel attenuated poliovirus in a novel poliovirus-susceptible animal model. Cancer Res, 67, pp. 2857-2864

Toyoda, H., Wimmer, E., \& Cello, J. (2011). Oncolytic polio therapy and immunization with poliovirus-infected cell lysate induces potent antitumor immunity against neuroblastoma in vivo. Int J Oncology, 38, pp. 81-87

Udono, H., \& Srivastava, P. (1994). Comparison of tumor-specific immunogenicities of stress induced proteins gp96, hsp90, and hsp70. J Immunol, 152, pp. 5398-5403

Ullrich, E., Bonmort, M., Mignot, G., Kroemer, G., \& Zitvogel, L. (2008). Tumor stress, cell death and the ensuing immune response. Cell Death Differ, 15, pp. 21-28

Vähä-Koskela, M., Heikkilä, J., \& Hinkkanen, A. (2007). Oncolytic viruses in cancer therapy. Cancer Lett, 254, pp. 178-216

Wheelock, E., \& Dingle, J. (1964). Observations on the repeated administration of viruses to a patient with acute leukemia: A preliminary report. $N$ Engl J Med, 271, pp. 645-651

White, R., Stanley, W., Johnson, J., Tyler, D., \& Seigler, H. (2002). Long-term survival in 2505 patients with melanoma with regional lymph node metastasis. Ann Surg, 235, pp. 879-887

Zitvogel, L., Tesniere, A., \& Kroemer, G. (2006). Cancer despite immunosurveillance: immunoselection and immunosubversion. Nat Rev Immunol, 6, pp. 715-727 


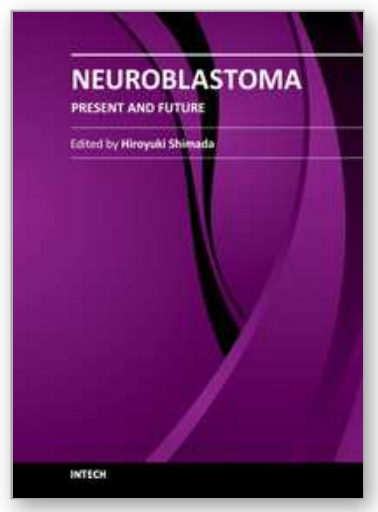

\author{
Neuroblastoma - Present and Future \\ Edited by Prof. Hiroyuki Shimada
}

ISBN 978-953-307-016-2

Hard cover, 366 pages

Publisher InTech

Published online 08, February, 2012

Published in print edition February, 2012

Neuroblastoma, once called "enigmatic", due to "unpredictable" clinical behaviors, is composed of biologically diverse tumors. Molecular/genomic properties unique to the individual tumors closely link to the clinical outcomes of patients. Establishing risk stratification models after analyzing biologic characteristics of each case has made a great success in patient management. However, the trend of improving survival rates in neuroblastoma over the last 30 years has started to level off, and currently available treatment modalities have almost reached to their maximized intensity. Furthermore, aggressive treatment causes significant long-term morbidities to the survivors. We really need to make the next step to the level of personalized medicine with more precise understanding of neuroblastoma biology. This book includes useful data and insights from the world's experts in this field. I believe this book can make an excellent contribution to all the investigators working hard and fighting for the children stricken by this disease.

\title{
How to reference
}

In order to correctly reference this scholarly work, feel free to copy and paste the following:

Hidemi Toyoda, Eckard Wimmer and Jeronimo Cello (2012). Oncolytic Poliovirus Therapy in a Mouse Model of Neuroblastoma: Preclinical Data Analysis and Future Studies, Neuroblastoma - Present and Future, Prof. Hiroyuki Shimada (Ed.), ISBN: 978-953-307-016-2, InTech, Available from:

http://www.intechopen.com/books/neuroblastoma-present-and-future/oncolytic-poliovirus-therapy-in-a-mousemodel-of-neuroblastoma-preclinical-data-analysis-and-future-

\section{INTECH}

open science | open minds

\section{InTech Europe}

University Campus STeP Ri

Slavka Krautzeka 83/A

51000 Rijeka, Croatia

Phone: +385 (51) 770447

Fax: +385 (51) 686166

www.intechopen.com

\section{InTech China}

Unit 405, Office Block, Hotel Equatorial Shanghai

No.65, Yan An Road (West), Shanghai, 200040, China

中国上海市延安西路65号上海国际贵都大饭店办公楼 405 单元

Phone: +86-21-62489820

Fax: $+86-21-62489821$ 
(C) 2012 The Author(s). Licensee IntechOpen. This is an open access article distributed under the terms of the Creative Commons Attribution 3.0 License, which permits unrestricted use, distribution, and reproduction in any medium, provided the original work is properly cited. 